\title{
Production of boron carbide powder by carbothermal synthesis of gel material
}

\author{
A K KHANRA \\ Department of Metallurgical and Materials Engineering, Indian Institute of Technology, Kharagpur 721 302, India
}

MS received 21 August 2006; revised 29 January 2007

\begin{abstract}
Boron carbide $\left(\mathrm{B}_{4} \mathrm{C}\right)$ powder has been produced by carbothermal reduction of boric acid-citric acid gel. Initially a gel of boric acid-citric acid is prepared in an oven at $100^{\circ} \mathrm{C}$. This gel is pyrolyzed in a high temperature furnace over a temperature range of $1000-1800^{\circ} \mathrm{C}$. The reaction initiation temperature range for $\mathrm{B}_{4} \mathrm{C}$ formation is determined by thermal analysis. The optimal pyrolysis temperature of $\mathrm{B}_{4} \mathrm{C}$ synthesis is investigated. During pyrolysis, the evaporation of boron-rich phases results in presence of free carbon in $\mathrm{B}_{4} \mathrm{C}$ powder. The electron micrographs and particle size analyser reveal the generation of fine $\mathrm{B}_{4} \mathrm{C}$ particles.
\end{abstract}

Keywords. $\quad B_{4} C$; carbothermal synthesis; gel material.

\section{Introduction}

Boron carbide is an advanced ceramic material. It occupies a significant place in the group of most important nonmetallic hard materials. It is the third hardest material known and hardest material produced in tonnage quantities. In 1883, Joly reported the preparation of boron carbide and identified it as $\mathrm{B}_{3} \mathrm{C}$ and then Moissan reported the production of $\mathrm{B}_{6} \mathrm{C}$. The stoichiometric formula of $\mathrm{B}_{4} \mathrm{C}$ was identified in 1934. The boron carbide has a rhombohedral structure with 12-atom icosahedral clusters which are linked by direct covalent bonds and through three-atom intericosahedral chains. Boron carbide has single phase throughout the entire range (Thevenot 1990; Spohn 1993). Its high wear and impact resistance and low specific weight makes it suitable for application in ball mills, nozzle, wheel dressing tools, wire drawing dies, rocket propellant light weight armour plates etc (Alizadeh et al 2004). It can also be used as a reinforcing material for ceramic matrix composites. It is an excellent neutron absorption material in nuclear industry due to its high neutron absorption coefficient (Sinha et al 2002). Boron carbide can be prepared by reaction of elemental boron and carbon powder, carbothermal route, reduction of $\mathrm{BCl}_{3}$ by $\mathrm{CH}_{4}$ at $1500^{\circ} \mathrm{C}$ by laser and low temperature synthesis from a $\mathrm{CCl}_{4}, \mathrm{BBr}_{3}$ and Na mixture (Sinha et al 2002; Shi 2003). Recently, Khanra and Godkhindi (2005) prepared ultrafine $\mathrm{B}_{4} \mathrm{C}$ powder by self-propagating high-temperature synthesis (SHS), whereas Carlsson et al (2002) prepared $\mathrm{B}_{4} \mathrm{C}$ whisker by carbothermal vapour-liquid-solid growth mechanism. In

(asit_iitkgp@yahoo.com) the present investigation, the $\mathrm{B}_{4} \mathrm{C}$ powder has been prepared from the pyrolysis of boric acid-citric gel material and the pyrolysed product is characterized by different techniques.

\section{Experimental}

Boric acid (99.9\% pure, Loba-Chemie, India) and citric acid $(99.5 \%$ pure and particle size, $99.8 \%$ pure, S. D. Fine Chem, India) were used as precursor materials for boron and carbon, respectively. A mixture $(10 \mathrm{~g})$ of boric acid and citric acid (molar ratio 12:7) was dissolved in distilled water and then the solution was heated in an oven at $100^{\circ} \mathrm{C}$ for $3 \mathrm{~h}$. The solution became golden yellow gel, which was crushed into powder for pyrolysis. The differential thermal analysis and thermogravimetric analysis (DTA/TG) (Perkin Elmer, Pyris Diamond TG/DTA, Japan) of crushed powder was carried out from room temperature to $1400^{\circ} \mathrm{C}$. The $\mathrm{DTA} / \mathrm{TG}$ was done in $\mathrm{XL}$ grade argon atmosphere and the rate of heating was $10,20^{\circ} \mathrm{C} / \mathrm{min}$. The crushed mass was next pyrolyzed over a temperature range of $1000-1800^{\circ} \mathrm{C}$ in a graphite resistance-heating furnace (Thermal Technology Inc, USA) with a continuous flow of XL grade argon gas. The phase analysis of the pyrolyzed product was carried out by XRD technique (Philips PW 1840, The Netherlands). The black pyrolyzed powder was burnt at $600^{\circ} \mathrm{C}$ for $2 \mathrm{~h}$ (air) for burning of unreacted carbon present in the product. The burnt product was also characterized by XRD. The morphology of the purified product was studied by a scanning electron microscope (SEM) (JEOL, JSM 840A, Japan). The particle size distribution of the product was determined by a particle size analyser (Malvern M7, UK) using the laser scattering 
technique. The transmission electron microscopic (TEM) studies on the leached and washed powder were carried out by putting the ultrasonically dispersed powders on a carbon coated copper grid using Philips electron microscope (CM 200, The Netherlands). The samples were analysed by $200 \mathrm{keV}$ electron beam during TEM investigations.

\section{Results and discussion}

The synthesized powder is found to be black in colour. The DTA/TG plot of gel at different rates of heating is shown in figure 1. It shows two endothermic peaks at lower temperatures due to melting and dissociation $\left(138^{\circ} \mathrm{C}\right.$ and $169^{\circ} \mathrm{C}$ ) of boric acid, respectively. But similar type of phenomenon is not observed for citric acid. This may be due to overlap or relatively a smaller magnitude of heat of melting and dissociation of citric acid precursors. The individual DTA/TG analysis reveals melting of citric acid at $157^{\circ} \mathrm{C}$ and then dissociation at $220^{\circ} \mathrm{C}$. The dissociation reactions are given below

$$
\begin{aligned}
& 2 \mathrm{H}_{3} \mathrm{BO}_{3} \rightarrow \mathrm{B}_{2} \mathrm{O}_{3}+3 \mathrm{H}_{2} \mathrm{O}, \\
& \mathrm{C}_{6} \mathrm{H}_{8} \mathrm{O}_{7} \cdot \mathrm{H}_{2} \mathrm{O} \rightarrow 3 \mathrm{C}+5 \mathrm{H}_{2} \mathrm{O}+3 \mathrm{CO} .
\end{aligned}
$$

Figure 1 shows presence of a big hump in the range 1050$1100^{\circ} \mathrm{C}$. This may be the indication of phase changes during pyrolysis. The XRD patterns of gel pyrolyzed at different temperatures are shown in figure 2 . The pattern shows presence of $\mathrm{B}_{2} \mathrm{O}_{3}$ as a major phase with $\mathrm{B}_{4} \mathrm{C}$ as a minor phase of gel pyrolyzed from $1000-1400^{\circ} \mathrm{C}$ range. The initial molar ratio (12:7) of boric acid and citric acid is equivalent

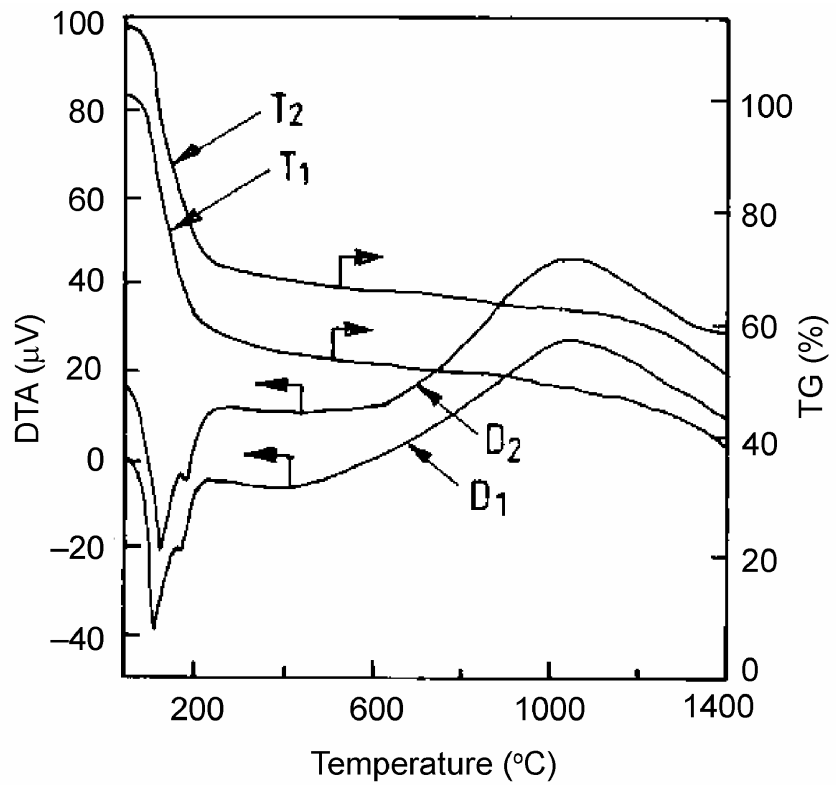

Figure 1. DTA/TG plot of gel material: $D_{1}, D_{2}$ are DTA at 10 , $20^{\circ} \mathrm{C} / \mathrm{min}$ and $T_{1}, T_{2}$ are TG at $10,20^{\circ} \mathrm{C} / \mathrm{min}$. to molar ratio of $2: 7$ of $\mathrm{B}_{2} \mathrm{O}_{3}$ and $\mathrm{C}$. The overall pyrolysis reaction of gel can be written as

$$
2 \mathrm{~B}_{2} \mathrm{O}_{3}+7 \mathrm{C} \rightarrow \mathrm{B}_{4} \mathrm{C}+6 \mathrm{CO} \text {. }
$$

The TG plot shows sharp decrease of weight due to $\mathrm{H}_{2} \mathrm{O}$ loss of the mixture (dissociation) and then uniform decrease of weight. A sharp decrease of weight is observed above $1000^{\circ} \mathrm{C}$, which may be due to weight loss due to $\mathrm{CO}$ gas generation. The weight losses of the pyrolyzed samples are found to be $\sim 77 \%$ and $80.2 \%$ at $1600^{\circ} \mathrm{C}$ and $1800^{\circ} \mathrm{C}$, respectively. As per (3), the theoretical weight loss is calculated to be $\sim 75 \%$. The higher observed weight losses may be due to the evaporation of boron oxide and boron sub-oxide at higher temperatures. The reaction of carbon could have occurred with both liquid boron oxide and gaseous boron sub-oxide $\left[\mathrm{B}_{2} \mathrm{O}_{2(\mathrm{~g})}\right]$. The rate of formation of gaseous boron sub-oxide increases with temperature (Alizadeh et al 2004). This indicates the $\mathrm{B}_{4} \mathrm{C}$ formation to occur through the gaseous $\mathrm{B}_{2} \mathrm{O}_{2}$. After $1500^{\circ} \mathrm{C}$, the liquid $\mathrm{B}_{2} \mathrm{O}_{3}$ phase starts to form gaseous $\mathrm{B}_{2} \mathrm{O}_{3}$. The kinetics of gaseous $\mathrm{B}_{2} \mathrm{O}_{3}$ phase formation is less than the rate of gaseous $\mathrm{B}_{2} \mathrm{O}_{2}$ formation (Alizadeh et al 2004). It is necessary to take some extra boric acid (reducing agent) in the reactant mixture to compensate the loss through the evaporation of $\mathrm{B}_{2} \mathrm{O}_{2}$ and $\mathrm{B}_{2} \mathrm{O}_{3}$. The XRD patterns of the sample pyrolyzed at 1600 and $1800^{\circ} \mathrm{C}$ show presence of unreacted carbon and $\mathrm{B}_{4} \mathrm{C}$ phase (figure 2 ). The intensity of carbon peak is found to increase at $1800^{\circ} \mathrm{C}$ as compared to $1600^{\circ} \mathrm{C}$. The amount of free carbon of pyrolyzed product is found to be $\sim 9.8$ and $12.7 \%$ at $1600^{\circ} \mathrm{C}$ and $1800^{\circ} \mathrm{C}$, respectively. The

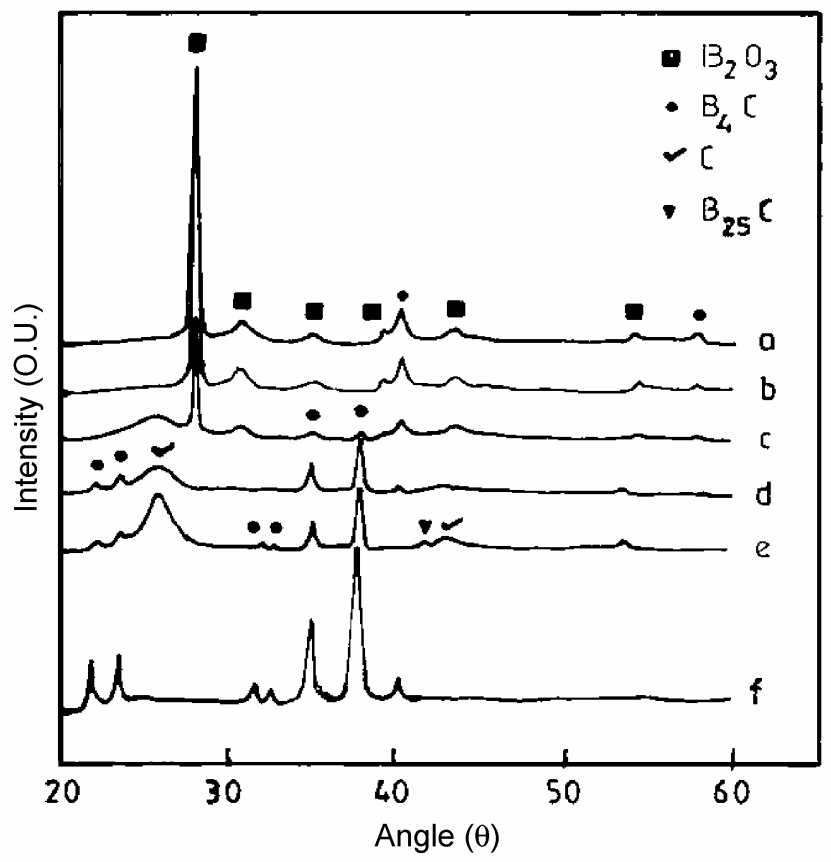

Figure 2. XRD patterns of gel pyrolyzed at different temperatures: a. 1000 , b. 1200 , c. 1400 , d. 1600 , e. $1800^{\circ} \mathrm{C}$ and f. after carbon removal (burning at $600^{\circ} \mathrm{C}$ ). 


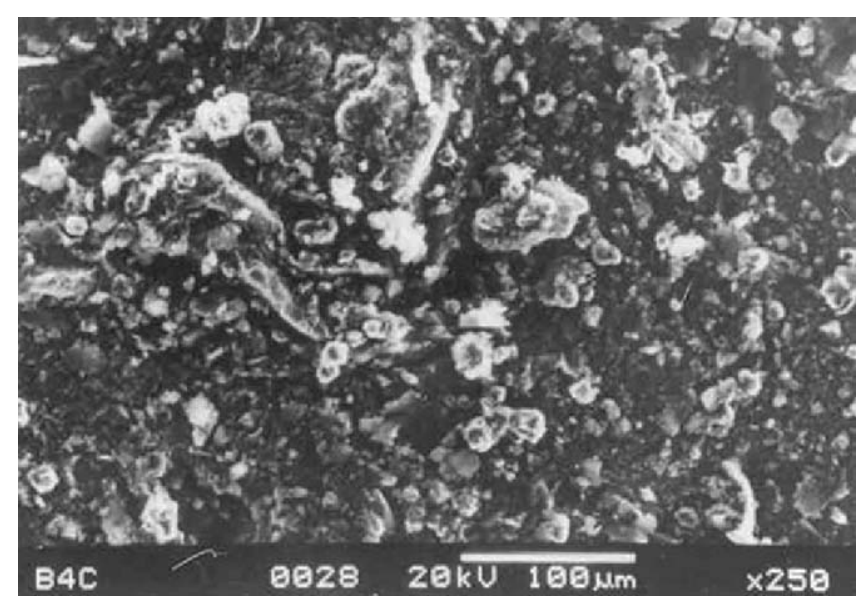

Figure 3. SEM image of purified powder pyrolyzed at $1600^{\circ} \mathrm{C}$.

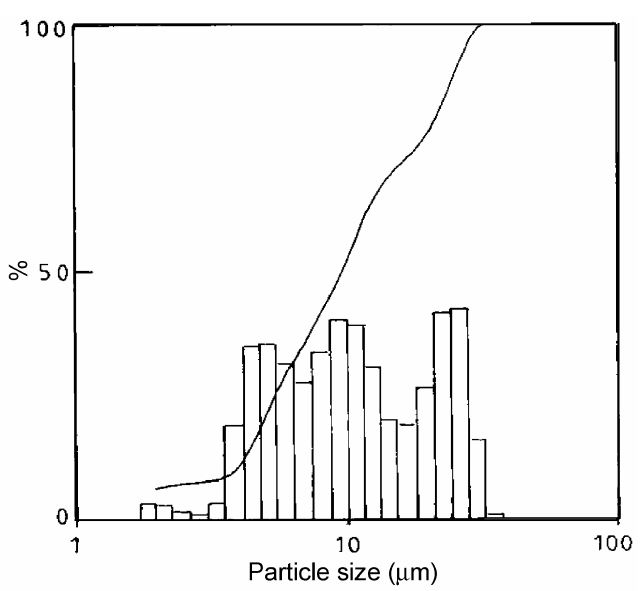

Figure 4. Particle size distribution of purified powder pyrolyzed at $1600^{\circ} \mathrm{C}$.
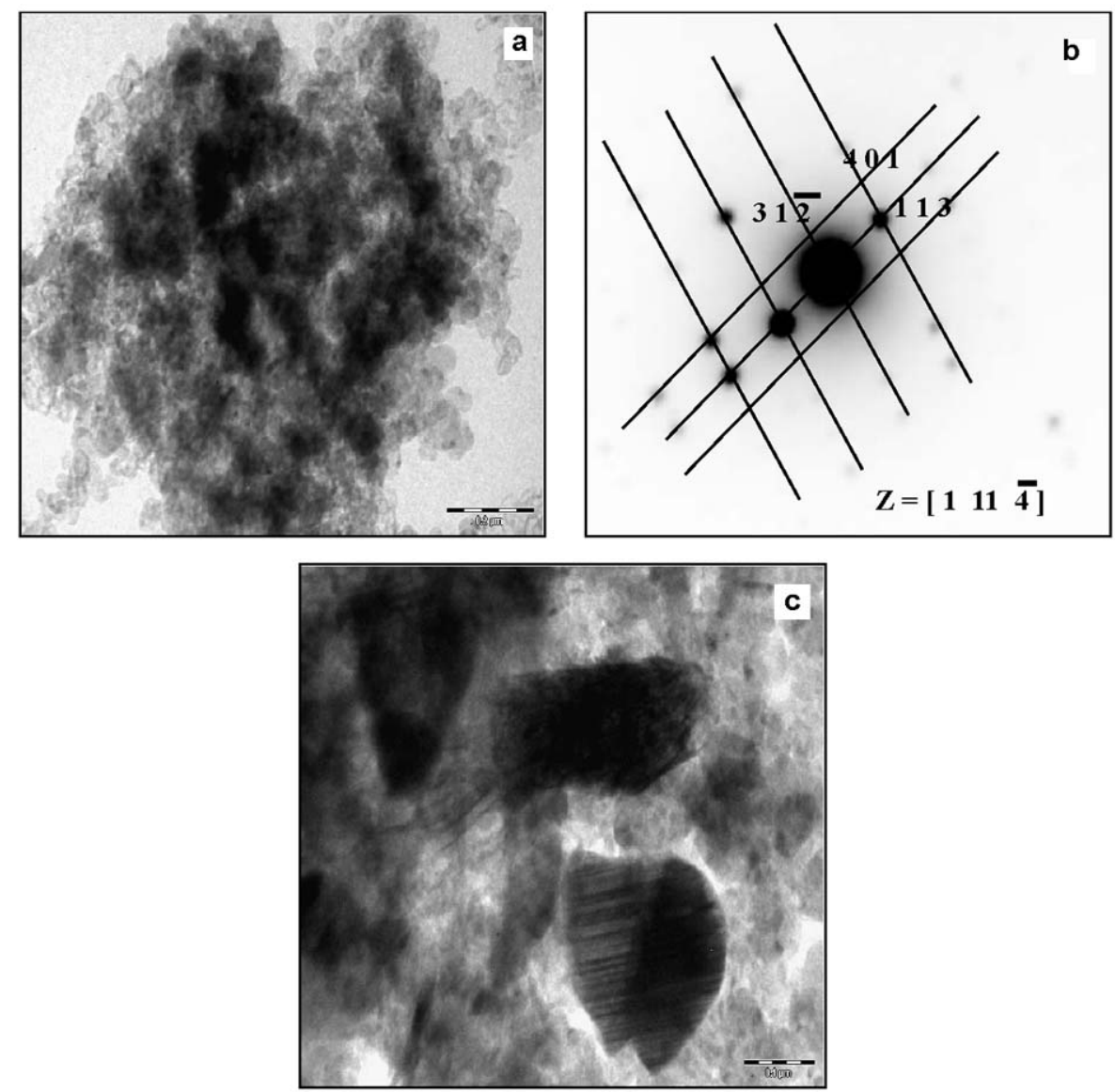

Figure 5. TEM images of purified powder pyrolyzed at $1600^{\circ} \mathrm{C}: \mathbf{a} \cdot \mathrm{B}_{4} \mathrm{C}$ powder, b $\mathrm{SAD}$ pattern and $\mathbf{c}$. twin formation in powder.

presence of free carbon in the pyrolyzed powder is possibly due to evaporation of more boron-rich phases from the mixture during pyrolysis. The pyrolysis at $1600^{\circ} \mathrm{C}$ may be the optimum temperature for production of $\mathrm{B}_{4} \mathrm{C}$ powder with minimum impurity (free carbon) from the gel material.
The XRD pattern shows absence of free carbon after removal of carbon (burning at $600^{\circ} \mathrm{C}$ for $2 \mathrm{~h}$ ) in case of gel pyrolyzed at $1600^{\circ} \mathrm{C}$, which indicates removal of carbon at $600^{\circ} \mathrm{C}$ (figure $2 \mathrm{f}$ ). It has also been seen that the amount of free carbon is much more when $\mathrm{B}_{4} \mathrm{C}$ is prepared from 
the mixture of $\mathrm{B}_{2} \mathrm{O}_{3}$ and amorphous carbon. It may be due to non-uniform mixture, which affects the kinetics of conversion of $\mathrm{B}_{4} \mathrm{C}$. The presence of small amount of fine carbon may help during densification of $\mathrm{B}_{4} \mathrm{C}$ (Sinha et al 2002). The SEM shows mainly agglomeration of fine spherical particles (figure 3 ). The particle size analysis of the product pyrolyzed at $1600^{\circ} \mathrm{C}$ shows bi-modal type of particle distribution (figure 4 ). The average particle size of $\mathrm{B}_{4} \mathrm{C}$ powder is found to be $\sim 9.4 \mu \mathrm{m}$. The TEM images of pyrolyzed powder are shown in figure 5. It shows agglomeration of fine particles and presence of defective structures like twins formation are also found. Such defects are generally formed in combustion synthesized powder due to high rate of cooling and shows higher sintered density than commercially available powder during pressureless sintering (Mishra et al 2004; Khanra et al 2005). The selected area diffraction (SAD) pattern shows presence of $\mathrm{B}_{4} \mathrm{C}$ planes (figure $5 \mathrm{~b}$ ). Presence of defects like twins is often found in the synthesized powder (figure 5c). Such defects are generally formed in the combustion synthesized powder due to high rate of cooling and shows higher sintered density than commercially available powder during pressureless sintering (Mishra et al 2004; Khanra et al 2005). A detailed TEM study regarding presence of defect structures are under progress.

\section{Conclusions}

The $\mathrm{B}_{4} \mathrm{C}$ powder can be produced by carbothermal reduction of gel material prepared from boric acid-citric acid mixture
During pyrolysis, the $\mathrm{B}_{4} \mathrm{C}$ formation starts over the temperature range of $1050-1100^{\circ} \mathrm{C}$. The optimum pyrolysis temperature of $\mathrm{B}_{4} \mathrm{C}$ is found to be at $1600^{\circ} \mathrm{C}$. The generation of fine $\mathrm{B}_{4} \mathrm{C}$ powder is confirmed from the SEM, particle size analysis and TEM study.

\section{Acknowledgements}

The author is grateful to Prof. M M Godkhindi, Indian Institute of Technology, Khargapur and Dr L C Pathak, National Metallurgical Laboratory, Jamshedpur, for extensive help and valuable suggestions during the experiments.

\section{References}

Alizadeh A, Nassaj E T and Ehsani N 2004 J. Eur. Ceram. Soc. 243277

Carlsson M, Garcia F J G and Johnsson M 2002 J. Cryst. Growth 236466

Khanra A K and Godkhindi M M 2005 J. Aust. Ceram. Soc. 4130 Khanra A K, Pathak L C and Godkhindi M M 2005 J. Am. Ceram. Soc. 881619

Mishra S K, Das S and Pathak L C 2004 Mater. Sci. \& Engg. A364 249

Shi L, Gu Y, Chen L, Qian Y, Yang Z and Ma J 2003 Solid State Commun. 15

Sinha A, Mahata T and Sharma B P 2002 J. Nucl. Mater. 301 165

Spohn M T 1993 Am. Ceram. Soc. Bull. 7288

Thevenot F 1990 J. Eur. Ceram. Soc. 6205 